\title{
Investigating effects of parasite infection on body condition of the Kafue lechwe (Kobus leche kafuensis) in the Kafue basin
}

\author{
Musso Munyeme ${ }^{1}$, Hetron M Munang'andu², John B Muma ${ }^{2}$, Andrew M Nambota', Demelash Biffa ${ }^{3}$, \\ Victor M Siamudaala ${ }^{4}$
}

\begin{abstract}
Background: The Kafue lechwe (Kobus leche Kafuensis), a medium-sized semi-aquatic antelope, is endemic to the Kafue basin of Zambia. The population of the Kafue lechwe has significantly dropped in the last decades leading to its subsequent inclusion on the red list of endangered species. In order to save the remaining population from extinction, it has become increasingly important that the impact of parasite infection and infestation on the Kafue lechwe is investigated.
\end{abstract}

Findings: Endoparasites accounted for the majority of parasites observed from a study of 40 Kafue lechwe occurring in the the Kafue basin. Amphistoma spp. were present in all animals examined, while Fasciola gigantica had a prevalence rate of 0.525 ( $95 \%$ Cl: 0.36 to 0.69) and species of Schistosoma 0.3 ( $95 \%$ Cl: 0.15 to 0.45 ). Among the ectoparasites, Strobiloestrous vanzyli, had a prevalence rate of 0.15 ( $95 \%$ Cl: 0.03 to 0.27), while Rhipicephalus appendiculatus had a prevalence of 0.075 (3/40). Our findings indicate that body condition was not influenced by the parasitic infestation in Kafue lechwe. There was no association between sex and parasitic burden (odds ratio = $0.3,95 \%$ Cl: 0.8-1.3). However, an association between age and parasitic burden was observed as older animals above 15 years were more likely to get parasite infections than those aged between 1-5 years (odds ratio $=1.5$, $95 \% \mathrm{Cl}: 1.1-2.4)$.

Conclusion: Overall, there was no evidence that parasitic infections and infestations adversely affected the lechwe population on the Kafue basin. These findings indicate that ecto- and endo-parasite infestation might not play a significant role in reducing the Kafue lechwe population on the Kafue basin.

\section{Background}

The Kafue lechwe antelope (Kobus leche kafuensis) is the predominant wildlife species of the Kafue basin. These antelopes are lek-breeders and share their habitat with other wild and domestic species. They are semiaquatic and medium sized antelopes that live in large groups close to water bodies or marsh places [1]. The lechwe population on the Kafue basin has steadily declined from an estimated 80,000 in 1975 to 41,000 in $2001[2,3]$ leading to its recent inclusion on the IUCN Red list of threatened species [4]. This has led the

\footnotetext{
* Correspondence: hetron.munangandu@gmail.com

${ }^{2}$ Norwegian School of Veterinary Sciences, Department of Basic Sciences and Aquatic Medicine, Section of Aquatic Medicine and Nutrition, Ullevalsveien

72, P.O. Box 8146 Dept, NO-0033 Oslo, Norway

Full list of author information is available at the end of the article
}

Zambia wildlife Authority (ZAWA) to embark on conservation programs aimed at saving the remaining population from going into extinct. In order to achieve this, it has become increasingly important to investigate all potential factors likely to contribute to the decline of the Kafue lechwe population.

The Kafue basin ecosystem harbors various species of ecto- and endo parasites that infest both wild and domestic animals [5-7]. Studies by Kampamba [8] and Kapungwe [3] indicate that ecological changes and animal diseases are the major factors reducing the Kafue lechwe population in the Kafue basin. Gallagher et al [9] estimated that parasitic diseases accounted for approximately $14 \%$ annual mortality of the lechwe population each year and formed a major factor limiting population growth. Previous studies have focused on identifying the

\section{Ciomed Central}


species of parasites infesting the Kafue lechwe $[9,10]$, did not investigate on the impact of these parasites. In cattle parasitic infestations have been associated with considerable weight loss, which in some cases have led to mortalities depending on the severity of the infection [11]. In evaluating animal health conditions, body-condition is used as a proxy for evaluating the health status of wildlife within a habitat and is thus a useful tool for assessing the impact of diseases on wild species [12]. In the present study, we investigated the effect of the ecto and endo-parasites found in the Kafue basin on body condition of free ranging Kafue lechwe, as a way of examining the role of parasite infestation on reducing the Kafue lechwe population.

\section{Materials and methods}

\section{Study area and animals}

The study was conducted in the Kafue basin (Figure 1). The Kafue basin covers an area of about $6,000 \mathrm{~km}^{2}$, encompassing the Blue Lagoon National Park $\left(420 \mathrm{~km}^{2}\right)$, Lochinvar National Park $\left(410 \mathrm{~km}^{2}\right)$ and Kafue GMA $\left(5,175 \mathrm{~km}^{2}\right)$. This area supports grazing for cattle in the dry season resulting for active interaction between livestock and wildlife. Samples were obtained from six Kafue lechwe herds occurring within game management areas (GMA) (Figure 1). GMAs are ecological buffer zones between communal lands and National Parks (NP) allowing for the co-existence of livestock $[13,14]$.

Given the endangered status of the Kafue lechwe [4], only 40 animals ( 20 females and 20 males) were sacrificed by ZAWA for the purpose of parasite investigations between October and December 2005. Ethical approval, under special license number 00113, was issued by the Zambia Wildlife Authority the sole custodians of wildlife in Zambia as stipulated in Section 37 of the Zambia Wildlife Act of the laws of the Republic of Zambia. Animals were aged using ring patterns on the horns as well as tooth development and wear $[15,16]$.

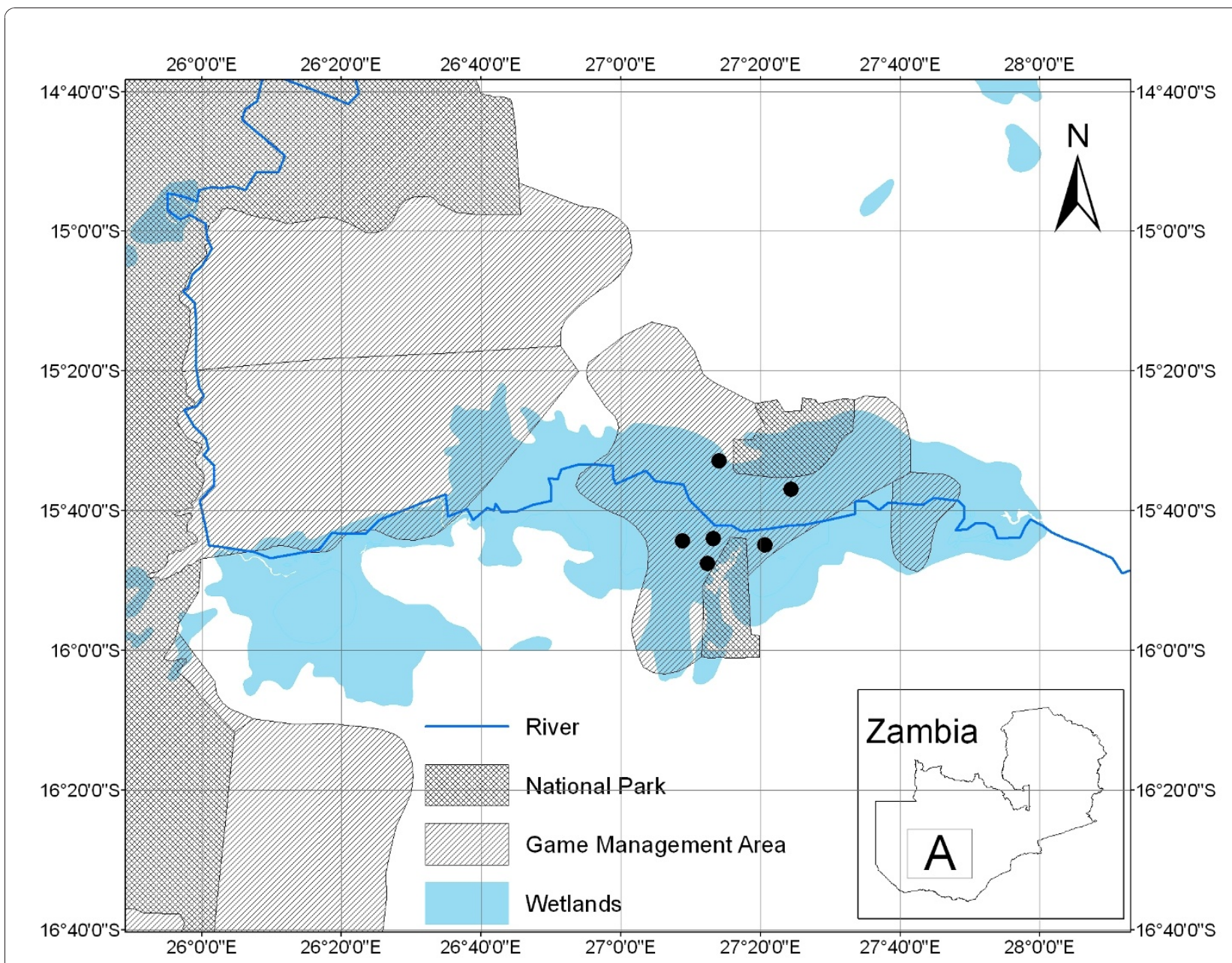

Figure 1 Map of the Kafue basin showing the location of National Parks and Game Management Areas being partially covered by the wetlands. Black dots show the sampling sites. The insert shows the map of Zambia with A showing the study area. 
Examination of carcasses was carried out as described by Gracey [17]. Body condition was graded using the kidney fat index (KFI) as described by Riney $[18,19]$. The amount of fat removed from the kidneys was weighed and divided by the total weight of the kidneys for each animal to get the index. Each carcass was allocated a score of 1 (poor: almost no fat); 2 (average: fair fat amount present); or 3 (good: plentiful fat, completely obscuring the kidneys).

\section{Sample collection and examination}

All animals were eviscerated followed by visual inspection and digital palpation of all body organs. Contents of the thoracic cavity were examined separately. Each component of the digestive system was processed separately with the contents from each segment being placed in separate bottles for laboratory examination. Schistosoma matteii in the mesenteries were collected using forceps and counted at the sampling sites. The liver was incised and examined for the presence of flukes. Visceral contents from each organ were emptied into a bucket and the mucosa washed thoroughly in water with firm digital pressure.

Quantification of the parasites was achieved by sieving and sedimentation following the method described by Taira et al [20], while egg counts of Schistosoma matteii were examined as described by Lawrence [21]. Cysts were excised from the heart muscles and evaginated from cyst membranes using methods described by Edgar [22] and Gonzalez et al [23]. They were later identified as cysticercus of Taenia saginata as described by Okafor [24] and Opara et al [25].

\section{Statistical analysis}

All observations were recorded in Microsoft Excel and later transferred to $\mathrm{STATA}^{\mathrm{Tm}} \mathrm{V} / \mathrm{SE} 10$ (Stata Corp, http://www.stata.com) for analysis. Logistic regression was used to determine the associations between body condition (based on the KFI) and parasite infection while the ROC test was used to determine the reliability of the model. Pearson's chi-square was used to determine the correlation of concurrent infections between different parasites.

\section{Results}

\section{Descriptive analysis}

Five genera of endo-parasites and two species of ectoparasites were identified (Table 1). The endo-parasites comprised of Schistosoma mattei isolated from the mesenteric veins, Fasciola gigantica from the liver and species of Amphistoma from the abomasum and rumen. Species of Setaria were isolated from the peritoneal cavity in the abdomen, while cysts of cysticercus of Taenia saginata were collected from the muscles of the heart, tongue and inter-coastal region. Ectoparasites included oestrid larvae (Strobiloestrous vanzyli) isolated from the subcutis of the back and dorsal aspect (Table 2) and Rhipicephalus appendiculatus obtained from different body parts of the skin surface (Table 2).

Fasciola gigantica was the second most prevalent endoparasite at a proportion of $52.5 \%(21 / 40)$ after species of Amphistosoma found in virtually all animals screened. Concurrent infections of Amphistosoma and Schistosoma mattei accounted for 17.5\% (7/40), species of Amphistosoma and Fasciola gigantica 20\% (8/40), Schistosoma mattei and Fasciola gigantica 17.5\% (8/40), while a combination of all trematodes (trematodes Amphistosoma species, Fasciola gigantica and Schistosoma mattei) accounted for $12.5 \%$ (5/40). Co-infections of all trematodes and nematodes (Setaria spp.) accounted for 5\% (2/ $40)$, while a combination of trematodes, nematodes and cestodes (cysts) accounted for $2.5 \%(1 / 40)$. There was a correlation $(\mathrm{r}=0.361, \mathrm{p}<0.022)$ between amphistosome and schistosome infections.

\section{Logistic regression analysis}

Our findings from the predictive logistic regression model indicate that body condition based on the KFI was not influenced by parasite infestation (Table 3). We also observed that parasite burden was not influenced by sex. However, age had an influence on parasite burden because older animals above 15 years were 1.5 times more prone to

Table 1 Crude parasitic infection in lechwe antelopes across the two sampling areas (Lochinvar and Blue Lagoon) $(n=40)$, indicative of crude prevalence values per type of parasite (October to December, 2005)

\begin{tabular}{|c|c|c|c|}
\hline Parasite & No. of Lechwes tested & Proportion of Positive findings(\%) & 95\% Confidence Interval \\
\hline Amphistoma spp. & 40 & 100 & - \\
\hline Schistosoma spp. & 40 & 30 & {$[15.2-44.8]$} \\
\hline Cysticercus bovis & 40 & 15 & {$[3.4-26.6]$} \\
\hline Fasciola gigantica & 40 & 52.5 & {$[36.3-68.7]$} \\
\hline Strobiloestrous vanzyli & 40 & 15 & {$[3.4-26.6]$} \\
\hline Wireworms* & 40 & 35 & {$[19.5-50.4]$} \\
\hline Ticks & 40 & 17.5 & [5.2-29.8] \\
\hline
\end{tabular}

*These worms were found in the free space of the peritoneum 
Table 2 Factors assessed in relation to parasite infestation in the Kafue lechwe antelopes $(n=40)$, showing proportions of distribution according to various levels (October to December, 2005)

\begin{tabular}{lccr}
\hline Variable & Level & \% proportion & 95\% Cl \\
\hline Sex & Females & 47.5 & {$[31.3-63.7]$} \\
& Males & 52.5 & {$[36.3-68.7]$} \\
\hline Age & $1-5$ years & 5 & {$[0-12]$} \\
& $5-10$ years & 60 & {$[44.1-75.9]$} \\
& $10-15$ years & 27.5 & {$[13-41.9]$} \\
\hline Body Condition Score & Good & 7.5 & {$[0-16]$} \\
& Fair & 12.5 & {$[60.9-89]$} \\
& Poor & 12.5 & {$[1.8-23.2]$} \\
\hline
\end{tabular}

infection than those aged 1-5 years (odds ratio $=1.5,95 \%$ CI: 1.1-2.4). The Hosmer-Lemeshow goodness-of-fit check showed that the model fitted the data well at $\mathrm{ROC}=0.76$.

\section{Discussion}

In ecological management, monitoring body condition of wild game is an important tool for monitoring the nutritional conditions of the habitat, and such information can also be used to assess the negative effect of parasites on the host [12]. Although several techniques for estimating body condition in wild ungulates have been developed [26,27], the kidney fat index (KFI) is the most widely used technique because it is regarded as the most reliable indicator of body condition in wild game [26]. Hence, in the present study, we investigated the impact of worm infestations on body condition of the Kafue lechwe by using the KFI as a proxy measure. Stien et al [28] pointed out that timing in carrying out observational studies aimed at detecting the impact of worm infestation on susceptible hosts is crucial because it is important to take into account the lag phase between the time of infection and the maximum parasite intensity in the infected hosts. Phiri et al [5] observed that increase in worm infection in the Kafue basin begins in June/July when the floods recede extending up to November/December when the rain season begins on the Kafue basin. Taking these observations into account, we carried out our investigations between October and December during the peak of the dry season when the parasite intensity is expected to be high in the infected animals. We only managed to evaluate 40 Kafue lechwe antelopes because these wild animals are protected by law because of the endangered nature of the Kobus leche kafuensis subspecies [4].

Our findings indicate that there was no statistically significant association between KFI and parasitic burden (Table 3), suggesting that the observed parasitic infections were unlikely to cause adverse body conditions in
Table 3 Results from a predictive logistic regression model for parasitic infection in Kafue lechwe antelopes ( $n=40)$-October to December, 2005

\begin{tabular}{llccc}
\hline Variable & Level & OR & P-Value & $\mathbf{9 5 \% ~ C l}$ \\
\hline Body C score & Good & 1 & - & - \\
& Fair & 0.4 & 0.53 & $0.6-1.1$ \\
& Poor & 0.2 & 0.19 & $0.1-1.4$ \\
\hline Age category & $1-5$ yrs & 1 & - & - \\
& 5-10 yrs & 1.2 & 0.00 & \\
& $10-15$ yrs & 0.9 & 0.01 & $0.6-1.2$ \\
& $>15$ yrs & 1.5 & 0.03 & $1.1-2.4$ \\
\hline Sex & Male & 1 & - & - \\
& Female & 0.34 & 0.15 & $0.8-1.3$
\end{tabular}

Assessment of the model fit to the observed data showed insignificant differences between observed and predicted values $\left(H L\left(\chi^{2}\right)(7)=6.43 ; p=\right.$ $0.49)$, hence indicating its high validity. The reliability of the model was relatively high ( $\mathrm{ROC}=0.76)$.

the infected animals. These findings suggest that at present, parasitic infections might not play a pivotal role to lechwe debilitation and consequently to population reduction on the Kafue basin. This is contrary to observation made by Gallagher et al [9], who reported that worm infestation was estimated to kill about $14 \%$ of the Kafue lechwe in the Kafue basin and suggested that worm infections were likely to be the major cause of the population reduction observed in the Kafue lechwe antelopes. However, age was shown to have a significant effect, as animals older than 15 years were one and half times more likely to carry parasites than those aged between 1 and 5 years (odds ratio $=1.5$, 95\% CI: 1.1 2.4). Sex had no influence on the parasitic burden. Gallagher et al [9] recorded a higher prevalence of fasciolosis in females than males, while Stafford [10] recorded a higher prevalence in the males than the females. The variations obtained from the two studies $[9,10]$ suggest that sex has no influence on parasitic burdens in lechwe and this supports our current findings.

Tick infestation rates of $17.5 \%(7 / 40)$ in our study are lower than those associated with low productivity and loss of weight gain in cattle $[29,30]$. This could be attributed to the semi aquatic nature of the lechwe, which spends most of its time in water submerged up to shoulder. It is likely that the aquatic tendency might not support the survival of most ticks. Similarly, Stafford [10] recorded a low prevalence of tick infestation on lechwe in the Kafue basin. Apart from ticks, oestrid larvae (Strobiloestrous vanzyli) were also observed in lechwe. These parasites are common in lechwe, and their presence has not been linked to mortalities in lechwe [10].

\section{Conclusion}

This study highlights species of parasites present in the Kafue lechwe antelope and provides a broad assessment 
of body condition relative to parasite loads. Based on these comparisons, parasite load does not appear to have a significant impact on the health and condition of lechwe. Therefore, factors other than parasites should be considered in future investigations designed to evaluate factors most important to maintenance of a viable lechwe population in the Kafue basin.

\section{Acknowledgements}

The authors are grateful to the Zambia Wildlife Authority (ZAWA) for providing the study animals and the School of Veterinary Medicine at the University of Zambia (UNZA) in Lusaka for their kind support by providing laboratory equipment and materials used in the study.

\section{Author details}

'Department of Disease Control, School of Veterinary Medicine, University of Zambia, P.O. Box 32379 Lusaka, Zambia. ${ }^{2}$ Norwegian School of Veterinary Sciences, Department of Basic Sciences and Aquatic Medicine, Section of Aquatic Medicine and Nutrition, Ullevalsveien 72, P.O. Box 8146 Dept, NO0033 Oslo, Norway. ${ }^{3}$ Center for Epidemiology and Biostatistics, Norwegian School of Veterinary Science, P.O. Box 8146, N-0033, Oslo, Norway. ${ }^{4}$ Zambia Wildlife Authority, Private bag 1, Chilanga, Zambia.

\section{Authors' contributions}

MM was involved in the sampling, data collection and analysis and preparation of the manuscript. HMM was involved in the sampling, data collection and preparation of the manuscript. AMN was involved in sampling and data collection. JBM was involved in the sampling, data collection and analysis as well as the preparation of the manuscript. DB was involved in data analysis and manuscript writing. VMS was involved in the sample collection and preparation of the manuscript. All authors participated in the preparation of the manuscript.

\section{Competing interests}

The authors declare that they have no competing interests.

Received: 2 August 2010 Accepted: 23 December 2010 Published: 23 December 2010

\section{References}

1. Sayer JA, van Lavieren LP: The ecology of the Kafue lechwe population of Zambia before the operation of the hydroelectricity dams on the Kafue river. E Afr Wildl J 1975, 13:9-37.

2. Kamweneshe B, Beilfuss R, Simukonda C: Population and distribution of Kafue lechwe and other large mammals on the Kafue flats, Zambia. Report to World Wide Fund for nature and Partners for Wetlands; 2002

3. Kapungwe EM: Carrying capacity changes and management of the Kafue lechwe (Kobus leche kafuensis) in Kafue Flats, Zambia. MSc Thesis. University of Zimbabwe, Harare, Zimbabwe; 1993.

4. IUCN red list of threatened species. Version 2009.1: IUCN SSC antelope specialist group 2008. Kobus leche. 2009 [http://www.iucnredlist.org].

5. Phiri AM, Phiri IK, Chota A, Monrad J: Trematode infections in freshwater snails and cattle from the Kafue wetlands of Zambia during a period of highest cattle-water contact. J Helminthol 2007, 81:85-92.

6. Speybroeck N, Madder M, Van Den Bossche P, Mtambo J, Berkvens N, Chaka G, Mulumba M, Brandt J, Tirry L, Berkvens D: Distribution and phenology of ixodid ticks in southern Zambia. Med Vet Entomol 2002, 16:430-41

7. Wright CA, Southgate VR, Howard GW: Life-cycles of some amphistome flukes in Zambia. J Helminthol 1979, 53:251-2.

8. Kampamba G: Ecology of kafue lechwe (Kobus Leche Kafuensis):The influences of resource limitation, disease and poaching on population regulation. Harare, Zimbabwe: University of Zimbabwe; 1998.

9. Gallagher J, Macadam I, Sayer J, van Lavieren LP: Pulmonary tuberculosis in free living lechwe in Zambia. Trop Anim Health Prod 1972, 4:213.

10. Stafford KJ: A review of diseases of parasites of the Kafue lechwe (KobusLeche-Kafuensis). J Wildl Dis 1991, 27:661-7.
11. Forbes $A B$, Huckle CA, Gibb MJ, Rook AJ, Nuthall R: Evaluation of the effects of nematode parasitism on grazing behaviour, herbage intake and growth in young grazing cattle. Vet Parasitol 2000, 90:111-8.

12. Wilson K, Bjornstad ON, Dobson AP, Merler S, Poglayen G, Randolph SE, Read AF, Skorping A: Heterogeneities in macroparasite infections: patterns and processes. In: The ecology of wildlife diseases.Edited by: Hudson PJ, Rizzoli A, Grenfell BT, Heesterbeek H, Dobson AP. Oxford University Press, New York; 2002.

13. Balkrishna M, Ndhlovu DE: Wildlife utilization and local people; A case study in Upper Lupande game management area, Zambia. Environ Conserv 1992, 19:135-44.

14. Lewis $D$, Kaweche $G B$, Mwenya A: Wildlife conservation outside protected areas - lessons from an experiment in Zambia. Conservation Biology 1990, 4:171-80.

15. Grimsdell JJR: Age determination of the African buffalo, Syncerus caffer sparrman. E Afri Wildl J 1973, 11:54

16. Jolles AE: Population biology of African buffalo (Syncerus caffer) at Hluhluwe-iMfolozi Park, South Africa. Afr J Ecol 2007, 45:398-406.

17. Gracey JF: Meat hygiene service. Vet Rec 1991, 129:204.

18. Riney T: Evaluating condition of free-ranging red deer (Cervus elephas), with special reference to New Zealand. N Z J Sci Tech 1955, 36:439-63.

19. Riney T: A field technique for assessing physical condition in some ungulates. J Wildl Man 1960, 24:92-4.

20. Taira R, Suzuki K, Boray JC: Detection and quantification of Faciola eggs in cattle using the beads technique. Jpn J Vet Parasitol 1983, 32:279-86.

21. Lawrence JA: Examination of ruminal faeces for schistosome eggs. Rhodesia Vet J 1970, 1:49-52.

22. Edgar SA: Artificial evagination of larval tapeworms. Tans Kans Acad Sci 1940, 43:397-9.

23. Gonzalez AE, Falcon N, Gavidia C, Garcia HH, Tsang VC, Bernal T, Romero M, Gilman RH: Treatment of porcine cysticercosis with oxfendazole: a doseresponse trial. Vet Rec 1997, 141:420-2.

24. Okafor FC: Epizootiology of Cysticercus bovis in Imo State, Nigeria. Angew Parasitol 1988, 29:25-30.

25. Opara MN, Ukpong UM, Okoli IC, Anosike JC: Cysticercosis of slaughter cattle in southeastern Nigeria. Impact of Emerging Zoonotic Diseases on Animal Health 2006, 1081:339-46.

26. Takatsuki S: Kidney fat and marrow fat indices of the sika deer population at Mount Goyo, northern Japan. Ecol Res 2000, 15:453-7.

27. Stevenson RD, Woods WA: Condition indices for conservation: new uses for evolving tools. Integr Comp Biol 2006, 46:1169-90.

28. Stien A, Irvine RJ, Ropstad E, Halvorsen O, Langvatn R, Albon SD: The impact of gastrointestinal nematodes on wild reindeer: experimental and cross-sectional studies. J Anim Ecol 2002, 71:937-45.

29. Pegram RG, Lemche J, Chizyuka HG, Sutherst RW, Floyd RB, Kerr JD, McCosker PJ: Effect of tick control on liveweight gain of cattle in central Zambia. Med Vet Entomol 1989, 3:313-20.

30. Pegram RG, Chizyuka HG: The impact of natural infestations of ticks in Zambia on the productivity of cattle and implications for tick control strategies in central Africa. Parasitol 1990, 32:165-75.

doi:10.1186/1756-0500-3-346

Cite this article as: Munyeme et al:: Investigating effects of parasite infection on body condition of the Kafue lechwe (Kobus leche kafuensis) in the Kafue basin. BMC Research Notes 2010 3:346.

\section{Submit your next manuscript to BioMed Central and take full advantage of:}

- Convenient online submission

- Thorough peer review

- No space constraints or color figure charges

- Immediate publication on acceptance

- Inclusion in PubMed, CAS, Scopus and Google Scholar

- Research which is freely available for redistribution 